\title{
Identification of Candidate Genes and Gene Networks Specifically Associated with Analgesic Tolerance to Morphine
}

\author{
Jenica D. Tapocik, ${ }^{1}$ Noah Letwin, ${ }^{2}$ Cheryl L. Mayo, ${ }^{1}$ Bryan Frank, ${ }^{2}$ Troung Luu, ${ }^{2}$ Ovokeraye Achinike, ${ }^{2}$ Carrie House, ${ }^{2}$ \\ Russell Williams, ${ }^{2}$ Greg I. Elmer, ${ }^{1}$ and Norman H. Lee ${ }^{2}$ \\ ${ }^{1}$ Maryland Psychiatric Research Center, Department of Psychiatry, University of Maryland, Baltimore, Baltimore, Maryland 21228, and ${ }^{2}$ Department of \\ Pharmacology and Physiology, George Washington University Medical Center, Washington, DC 20037
}

\begin{abstract}
Chronic morphine administration may alter the expression of hundreds to thousands of genes. However, only a subset of these genes is likely involved in analgesic tolerance. In this report, we used a behavior genetics strategy to identify candidate genes specifically linked to the development of morphine tolerance. Two inbred genotypes [C57BL/6J (B6), DBA2/J (D2)] and two reciprocal congenic genotypes (B6D2, D2B6) with the proximal region of chromosome 10 (Chr10) introgressed into opposing backgrounds served as the behavior genetic filter. Tolerance after therapeutically relevant doses of morphine developed most rapidly in the B6 followed by the B6D2 genotype and did not develop in the D2 mice and only slightly in the D2B6 animals indicating a strong influence of the proximal region of Chr10 in the development of tolerance. Gene expression profiling and pattern matching identified 64, 53, 86, and 123 predisposition genes and 81, 96,106 , and 82 tolerance genes in the periaqueductal gray (PAG), prefrontal cortex, temporal lobe, and ventral striatum, respectively. A potential gene network was identified in the PAG in which 19 of the 34 genes were strongly associated with tolerance. Eleven of the network genes were found to reside in quantitative trait loci previously associated with morphine-related behaviors, whereas seven were predictive of tolerance (morphine-naive condition). Overall, the genes modified by chronic morphine administration show a strong presence in canonical pathways representative of neuroadaptation. A potentially significant role for the micro-RNA and epigenetic mechanisms in response to chronic administration of pharmacologically relevant doses of morphine was highlighted by candidate genes Dicer and H19.
\end{abstract}

\section{Introduction}

The therapeutic value of opioids for pain relief is well established. Repeated opioid administration, however, can lead to a progressive decline in analgesic efficacy. Extensive research into the mechanisms involved in analgesic tolerance has provided substantial insight into its neurobiology (Williams et al., 2001). However, despite recent advances, the cellular and molecular alterations downstream of the primary effects at the $\mu$-opioid receptor $(\mu \mathrm{OR})$ are complex and not well understood (Law et al., 2000).

One strategy to discover the mechanisms of the behavioral effects of morphine is to identify regions of the genome associated with these traits through linkage analysis. Behavior genetic investigations of morphine tolerance demonstrate a high degree of heritability (Mas et al., 2000; Kest et al., 2002; Liang et al., 2006). Behavioral quantitative trait locus (bQTL) mapping as-

Received Aug. 22, 2008; revised Nov. 30, 2008; accepted March 13, 2009.

This work was funded by National Institute on Drug Abuse-National Institutes of Health Grant DA015087 (G.I.E., N.H.L.). We also acknowledge Dr. Wade H. Berrettini and Thomas N. Ferraro for their valuable contribution of mice and consultation.

Correspondence should be addressed to either of the following: Greg I. Elmer, Maryland Psychiatric Research Center, Department of Psychiatry, University of Maryland, Baltimore, Maple and Locust Street, Baltimore, MD 21228 E-mail: gelmer@mprc.umaryland.edu; or Norman H. Lee, Department of Pharmacology and Physiology, George Washington University Medical Center, 2300 I Street, Washington, DC 20037, E-mail: phmnhl@gwumc.edu.

D0I:10.1523/JNEUROSCI.4020-08.2009

Copyright $\odot 2009$ Society for Neuroscience $\quad$ 0270-6474/09/295295-13\$15.00/0 signs a significant portion of the genotype-dependent variance in morphine consumption and acute analgesia to the Mop2 locus on the proximal region of Chr10 (Berrettini et al., 1994a; Belknap et al., 1995; Bergeson et al., 2001; Doyle et al., 2006). This is a promising candidate region since the gene encoding the $\mu \mathrm{OR}(\mathrm{Oprm})$ is located in Mop2. Reciprocal congenic genotypes in which this region has been introgressed from the opposing background [C57BL/6J (B6) or DBA/2J (D2)] have been developed to further aid in the isolation of genetic factors (Bergeson et al., 2001; Ferraro et al., 2005). These studies have established a basic strategy with which to pursue specific genomic regions and candidate genes.

Large-scale gene expression profiling studies have also been used as a strategy to find candidate genes involved in tolerance. For instance, gene expression profiling in four opioid-naive (Korostynski et al., 2006) and morphine-treated mouse genotypes have identified basal and morphine-induced gene expression differences in the striatum (Korostynski et al., 2007) and nucleus accumbens (Grice et al., 2007) that may contribute to opioid-related phenotypes. However, none of the aforementioned studies anchored their gene expression results to withinsubjects derived behavioral data or investigated multiple brain regions especially to include those more directly involved in opioid-induced analgesia [i.e., periaqueductal gray (PAG)] and to assess region by genotype and drug interactions. Characterizing several brain regions and anchoring expression data 
to the same experimental protocol and dosing schedule may improve the likelihood of focusing on genes directly relevant to the phenotype in question.

Reciprocal congenic genotypes have been an excellent tool for confirming regions of the genome hypothesized to be involved in a particular trait (Bergeson et al., 2001; Ferraro et al., 2005). The purpose of our study was to use reciprocal congenics to investigate the promising role of proximal Chr10 in nociception and the acute and chronic effects of pharmacologically relevant doses of morphine. A behavior genetics approach (Letwin et al., 2006) was used to identify changes in gene expression directly related to morphine analgesic tolerance. In this manner, morphine-induced changes in gene expression that are irrelevant to this trait were filtered from the pool of genes. Only those genes specifically correlated to the trait of interest were identified as candidate genes significantly influencing the development of tolerance.

\section{Materials and Methods}

Animals

Adult male C57BL/6J (B6) and DBA/J (D2) (The Jackson Laboratory), D2B6 (Mop2 locus from B6 introgressed into D2 background), and B6D2 (Mop2 locus from D2 introgressed into B6 background) mice 60-120 d of age and weighing $\sim 21-28 \mathrm{~g}$ at the start of the experiment were used. The D2B6 and B6D2 mice were shipped to the Maryland Psychiatric Research Center from the University of Pennsylvania in which brother by sister mating continued to propagate the reciprocal strains. All animals were experimentally naive, housed in a temperature-controlled room $\left(21^{\circ} \mathrm{C}\right.$; 7:00 A.M. to 7:00 P.M. lights on), and given ad libitum access to chow and tap water during the entire experimental procedure.

The reciprocal congenic genotypes were generated in the following manner. The portion of the chromosome thought to account for a significant portion of variance in response to morphine was reciprocally introgressed between the parental genotypes, B6 and D2. The introgress protocol began with a $\mathrm{B} 6 \times \mathrm{D} 2$ intercross followed by backcross of the resulting $\mathrm{F}_{1}$ generation progeny to both parental genotypes. The backcross consisted of $F_{1}$ males and females being mated with progenitor mice. The $\mathrm{N}_{2}$ backcross progeny were genotyped using DNA extracted from tail snips at the time of weaning. Mice were then selected for subsequent rounds of backcross breeding based on heterozygosity at specific set of microsatellite DNA markers [B6D2: D10Mit75 $(2.0 \mathrm{cM})$ proximally to D10Mit124 $(15.0 \mathrm{cM})$ distally; D2B6: D10Mit75 $(2.0 \mathrm{cM})$ proximally to D10Mit61 $(32.0 \mathrm{cM})$ distally] (Ferraro et al., 2005). Ten serial backcross generations were created in a reciprocal manner. At generation $\mathrm{N}_{10}$, heterozygous mice were intercrossed and DNA from the $\mathrm{N}_{10} \mathrm{~F}_{1}$ progeny was analyzed to identify homozygous congenic mice $\mathrm{D} 2 \mathrm{~B} 6$ and reciprocal congenic genotype B6D2 (supplemental Fig. 1, available at www.jneurosci.org as supplemental material).

\section{Behavioral testing: nociception and analgesia}

Baseline sensitivity to pain and morphine-induced analgesia was measured by the hot-plate test (Harvard Hot Plate Analgesia Meter; Harvard Apparatus). The hot plate was maintained at a constant temperature of $55^{\circ} \mathrm{C}$ for all test conditions. Latency to paw lick (front or hind) or jump was used as the dependent measure. Under all experimental conditions, a cutoff time of four times the saline control value of each genotype was used to avoid tissue damage.

Baseline sensitivity. To determine the baseline sensitivity for each genotype, we examined the latencies of each genotype naive to morphine. Each genotype received one injection of saline and was tested $15 \mathrm{~min}$ later on the hot plate ( $n=6-9$ animals/genotype). Data were analyzed using a one-way ANOVA with genotype as a main effect.

Acute analgesic sensitivity to morphine. The subject was placed on the hot plate $15 \mathrm{~min}$ after subcutaneous injection of $0,0.3,1.0,3.0,10.0$, or $30.0 \mathrm{mg} / \mathrm{kg}$ morphine to determine the relative potency of morphine to produce analgesia. Each dose for each genotype consisted of six to nine animals and was tested for only $1 \mathrm{~d}$. A two-way ANOVA was performed for dose-response curves across genotype. Data were analyzed as the percentage of maximal analgesic response (\%MPE) as determined by the following formula: $100 *[($ test latency $)-($ saline baseline latency $)] \div[(4$ * baseline latency) - (baseline latency) $]$. The $\mathrm{ED}_{90}$ for each genotype was derived from the regression analysis of the linear portion of each doseresponse curve.

Chronic dosing and the development of tolerance. Analgesic tolerance to morphine was determined in three distinct experiments. In each experiment, the dose of morphine required to produce $\sim 90 \%\left(\mathrm{ED}_{90}\right.$ as determined above) of the maximal possible analgesic effect (\%MPE) was used to induce tolerance in each genotype. The $\mathrm{ED}_{90}$ dose of morphine for the D2, D2B6, B6, and B6D2 mice was as follows: 7.7, 7.7, 31.2, and 31.2 $\mathrm{mg} / \mathrm{kg}$, respectively. Mice were tested on the hot plate $15 \mathrm{~min}$ after injection. Saline or the $\mathrm{ED}_{90}$ dose of morphine was administered subcutaneously between the hours of 8:00 and 11:00 A.M.

The three experimental conditions were as follows: (1) "Three injection": For each genotype, two groups of mice (saline and morphine, $N=12-16$ /group) were tested once every other day during a $5 \mathrm{~d}$ period (i.e., Monday, Wednesday, Friday). Brains were harvested for gene expression analysis only in this experimental condition. (2) "Five injection, phenotypic confirmation": This test was performed as a complementary means to confirm the results of the three-injection schedule and to push the dosing to determine whether D2 mice would develop tolerance using a shorter injection interval and more injections. For each genotype, two groups of mice (saline and morphine, $N=6-9$ /group) were tested once every day during a $5 \mathrm{~d}$ period. (3) "Learning assessment": A subset of genotypes were run in a manner that would determine to what degree, if any, the response to morphine of a genotype was influenced by repeated exposure to the hot plate. In this experiment, the $\mathrm{ED}_{90}$ dose of morphine was given in a manner exactly the same as the three-dose group (once every other day; Monday, Wednesday, Friday); however, in one group, the hot plate was turned off until the final day of testing, whereas the hot plate was turned on $\left(55^{\circ} \mathrm{C}\right)$ for the other group as described above. Only $\mathrm{B} 6 \mathrm{D} 2$ and $\mathrm{B} 6$ mice were run in this experiment since they were the two genotypes that develop tolerance to a degree in which a learning component, if present, might be discerned ( $n=6-9$ /group per genotype). The mice were tested on the hot plate $15 \mathrm{~min}$ after injection.

In the three-injection and five-injection conditions, a one-way ANOVA was used to determine whether equianalgesic effects of morphine were produced on the first day of drug administration. A twoway (genotype by day) repeated-measures ANOVA was used to determine genetic differences in the analgesic effects of morphine across repeated administration. Morphine-treated mice at each respective dosing interval were compared with saline-treated mice tested under the same procedure. Data are presented as \%MPE. The threeinjection treatment was compared with the five-injection phenotype confirmation group using a three-way repeated-measures ANOVA (genotype by treatment paradigm by injection number). Two comparisons were made, one using the first three tests of each paradigm and second using the first, third, and fifth tests of the five-injection treatment paradigm (compared with the three tests of the threeinjection paradigm). In the learning assessment paradigm, a one-way ANOVA (heated vs room temperature hot plate) was conducted on the last test session to determine whether learning occurred as a result of repeated exposure to the hot plate.

\section{Dissection}

Brain tissue from the three-injection tolerance study was harvested from all four genotypes and treatment conditions ( $n=12-16$ mice/group) $3 \mathrm{~h}$ after the end of tolerance testing on the last test day. Each mouse was killed by $\mathrm{CO}_{2}$ asphyxiation followed by cervical dislocation and decapitation. A Plexiglas brain mold (David Kopf Instruments) was used to slice the fresh whole brain into coronal slices appropriate for each section desired (see below).

Using the atlas of Paxinos and Franklin (2001) as a reference, the following sections were taken: prefrontal cortex (PFC), interaurally $5.90-3.70 \mathrm{~mm}$, from the dorsal-most point to $2.25 \mathrm{~mm}$ ventrally at a medial-lateral width of $1 \mathrm{~mm}$ centered on midline; ventral striatum (VS), 
interaurally $5.90-3.70 \mathrm{~mm}$, from a dorsal-ventral position of $3.75 \mathrm{~mm}$ ventrally to just short of the ventral surface (not including olfactory tubercle) and from a medial-lateral position $2.0 \mathrm{~mm}$ to midline (this region included regions of interest such as the nucleus accumbens, ventral pallidum, bed nucleus of the stria terminalis, and substantia innominata); temporal lobe (TL), interaurally $2.74-1.74 \mathrm{~mm}$ from the dorsalmost point at $3.80 \mathrm{~mm}$ to the ventral surface from a medial point of 1.80 $\mathrm{mm}$ laterally to the lateral surface; periaqueductal gray (PAG) containing dorsal raphe, interaurally 0.00 to $-1.16 \mathrm{~mm}$ from the dorsal point $1.80-$ $3.00 \mathrm{~mm}$ ventrally at a medial-lateral width of $1.5 \mathrm{~mm}$ centered on midline.

The PAG has consistently been implicated in nociception, antinociception, and tolerance (Tortorici et al., 2001). In addition, the VS (Manning et al., 1994), TL (Pavlovic et al., 1996; Nandigama and Borszcz, 2003), and PFC (Hardy and Haigler, 1985) have also been shown to play a role in nociception and the analgesic effects of opioids (Chudler and Dong, 1995; Zubieta et al., 2001). In addition to nociception and analgesia, these areas were of interest in terms of their role in conditioned reinforcement and the reinforcing properties of drugs of abuse (VS, PFC) (Wise, 1996; Shippenberg and Elmer, 1998; Everitt et al., 1999).

\section{Microarray gene expression profiling}

Tissue from the four brain regions was harvested for gene expression analysis on a 27,648 element mouse cDNA microarray using a common reference design (Letwin et al., 2006; Lee and Saeed, 2007). The microarray was comprised of the National Institute on Aging Ko set of 15,247 cDNA clones (Tanaka et al., 2000) and National Institute of Mental Health Brain Molecular Anatomy Project set of 11,136 cDNA clones, together representing $\sim 21,000$ distinct mouse genes. Each brain region from two to three subjects was pooled to obtain adequate tissue samples, thereby forming three to five independent replicates. Total RNA was prepared using Trizol reagent (Invitrogen) and the RNeasy mini kit (QIAGEN) as per manufacturers' instructions. Each pooled RNA sample was further divided into two equal aliquots to enable a technical replication known as a dye swap hybridization (Lee and Saeed, 2007). Thus, expression analysis of a brain region for a particular genotype and treatment was derived from three to five independent hybridizations and three to five corresponding dye swap hybridizations. For statistical analysis, a biological replicate experiment was defined as the average of an independent hybridization and its corresponding dye swap hybridization (i.e., five independent and five corresponding dye swap hybridizations yield five biological replicates). A hybridization experiment consisted of Cy5-labeled cDNA that was reverse transcribed from $15 \mu \mathrm{g}$ of pooled total RNA and cohybridized with Cy3-labeled cDNA synthesized from an equal amount of the Stratagene Universal Mouse Reference RNA. Dye swap hybridizations were performed by reversing the dyes for each of the RNA samples. Hybridizations were performed for $18-24 \mathrm{~h}$ at $42^{\circ} \mathrm{C}$ followed by washing in decreasing concentrations of SSC at room temperature and spun dry. Microarray image scanning, fluorescence intensity measurements, LOWESS data normalization, normalization across replicate experiments, experimental noise determination, and cluster analysis were performed as described previously (Teramoto et al., 2005; Letwin et al., 2006).

\section{Microarray gene expression analysis}

Gene expression values from saline- and morphine-treated subjects in four genotypes in four brain regions can be defined as $c g_{s r}$ or $m g_{s r}$, where $c$ is saline control, $m$ is morphine, $g$ is gene, $s$ is genotype, and $r$ is region. These data yield two base data sets: (A) control gene expression without morphine intervention $\left(c g_{s r}\right)$, and (B) gene expression after morphine administration $\left(m g_{s r}\right)$. From these two data sets, we derive an additional data set $(\mathrm{C})$, the change in gene expression relative to the mean value of the genotype and region control expression $\left(m g_{s r}-x c g_{s r}\right.$, or $\left.\Delta\right)$. Since the morphine expression data are important mostly in relation to the control levels, the $\Delta$ data set was emphasized over $m g_{s r}$ in future analyses and discussion. Statistical analysis for genotype-dependent differences in data sets $c g_{s r}$ and $\Delta$ was accomplished by an ANOVA with $10 \%$ false discovery rate (FDR) to control for type I error resulting from multiple comparisons (Reiner et al., 2003). The implementation of a 10\% FDR corresponded to an effective $\alpha$ value of $\leq 0.00787$ (data not shown). Subsequently, the significant genes were filtered for a minimum 1.5 -fold change across genotypes based on "self versus self" hybridizations in which aliquots of the same RNA sample were labeled separately with Cy3 and Cy5 dyes and cohybridized onto a microarray. Results from these control hybridizations (data not shown) and previous published studies (Yang et al., 2002; Lee et al., 2007; Liang et al., 2008) demonstrate that a $Z$-score of $\sim 2$ to 3 corresponds to a 1.4 -fold "difference," providing a metric for inherent assay noise. Significant genes displaying a $\leq 1.4$-fold change in the strain comparisons exhibited a low validation success rate $(\sim 50 \%)$ as assessed by quantitative real-time reverse transcription (RT)PCR (data not shown), whereas genes above this cutoff displayed a validation rate $(>90 \%)$ in line with the chosen FDR. We will refer to these statistically significant and filtered data sets as follows: (1) "genotype signature genes," $c g_{s r}$ genes that are differentially expressed under control conditions as a function of genotype in each brain region, and (2) "morphine signature genes," $\Delta$ genes that are significantly different as a function of genotype in each brain region.

\section{Association of gene expression with tolerance across genotypes}

The phenotypic endpoint used to define tolerance was set as [100(\%MPE on day 3)] for each genotype. This number reflects the diminution in analgesic efficacy by the end of the chronic treatment regiment and assigns a higher value to the genotypes showing the most tolerance by the end of the treatment. A two-tier analysis strategy was used to define candidate genes associated with the tolerance phenotype. First, genes had to exhibit significant genotypedependent expression differences (i.e., genotype signature and morphine signature genes). Second, the genotype signature or morphine signature genes must be significantly correlated $(p<0.05)$ with the tolerance phenotype as defined by pattern matching/feature selection (Pavlidis and Noble, 2001; Letwin et al., 2006). The subset of genotype signature genes that were significantly associated with tolerance are defined as candidate "predisposition" genes. The subset of morphine signature genes that were significantly associated with tolerance are defined as candidate "tolerance" genes.

Identification of regional conservation of enriched gene expression Biological themes associated with morphine signature genes were identified by using the three Gene Ontology (GO) categories of molecular function, biological process, and cellular component in the Expression Analysis Systematic Explorer (EASE) application (Hosack et al., 2003), which is executable using TIGR Multi Experiment Viewer (TMEV) (available at www.tigr.org/softlab).

\section{Identification of gene networks and canonical pathways}

Identification of candidate genes that are highly interconnected or overrepresent a biological pathway may provide insight into molecular events that predispose or are causally related to the development of tolerance. To provide a functional framework to assist interpretation and narrow the candidate gene list to high value targets, gene networks and canonical pathways were explored using Ingenuity Pathway Analysis (IPA), Pathway Studio, the GO Consortium (www.geneontology.org), GenMAPP (www.genmapp.org), and Kyoto Encyclopedia of Genes and Genomes (www.genome.jp/kegg).

Ingenuity Systems is an online-based bioinformatics resource that algorithmically identifies gene networks and canonical pathways based on the gene lists. The gene lists uploaded into the database consisted of unique gene identifier (e.g., RefSeq, GenBank accession, Affymetrix ID), expression and correlation values. To identify gene networks, IPA rank orders the gene list in order of interconnectedness (triangle connectivity), and then adds genes to the top focus gene based on specific connectivity (how much the connections of a new gene overlap with the seed gene), and then combines smaller networks through the addition of linker genes found either in the uploaded list or IPA's Global Molecular Network. A $p$ value, the number of focus molecules $(f)$, and top functional potential is given for each network. The $p$ value is defined as the probability of finding $f$ or more Focus Genes in a set of $n$ genes randomly selected from the Global Molecular Network database using a right-tailed Fisher's exact test. All significant biological themes associated with 
these networks were subsequently cross-validated using Pathway Studio, GenMAPP, GO, and KEGG pathways. To identify canonical pathways, IPA quantifies the likelihood that the number of uploaded genes that overlap with any one of 163 established canonical pathways occurs at a level greater than chance using a right-tailed Fisher's exact test. The $p$ value and ratio value (number of molecules in a given pathway divided by total number of molecules that make up the pathway) are provided for each pathway.

\section{Association of predisposition and tolerance genes with} expression QTLs

Predisposition and tolerance genes in the PAG, PFC, TL, and VS were associated with expression QTLs (eQTLs) using the WebQTL module available at www.genenetwork.org/home.html. INIA Brain mRNA M430 (Jun06) RMA, VCU BXD PFC Sal M430 2.0 (Dec06) RMA, INIA Brain mRNA M430 (Jun06) RMA, HBP Rosen Striatum M430V2 (Apr05) RMA served as the databases for eQTL searches in the PAG, PFC, TL, and VS, respectively. Significant linkage of eQTL markers to correlated genes was defined by marker regression plots with 1000 permutations. The results from the permutation tests provide LRS (likelihood ratio statistics) scores that are suggestive, significant, or highly significant.

\section{Real-time RT-PCR validation of genes}

Expression levels of a portion of the genes were confirmed by real-time RT-PCR on an ABI Prism 7700 Sequence Detection System as previously described (Malek et al., 2002). Total RNA from PFC, TL, VS, and PAG in all genotypes was reverse transcribed using random primers following the manufacturer's instructions. The resulting cDNA was diluted and used as a template for quantitative PCR ( $\mathrm{qPCR}$ ). PCR primers were selected for specificity by the National Center for Biotechnology Information BLAST (basic local alignment search tool) of the mouse genome, and amplicon specificity was verified by first-derivative melting curve analysis using software provided by PerkinElmer and Applied Biosystems. Quantitation and normalization of relative gene expression were accomplished by using the comparative threshold cycle method as described previously (Joe et al., 2005). The following genes were identified by microarray analysis as differentially expressed across genotypes and subjected to RT-PCR validation: protein kinase C $\gamma$ (NM_011102), protein kinase A (NM_008854), cannabinoid receptor 1 (NM_007726), adenosine receptor 1 (NM_001008533), and dicer1 (NM_148948). The expression of the "housekeeping" genes carnitine acetyltransferase (NM_007760), peptidylprolyl isomerase-like 4 (NM_026141), and succinate-CoA ligase $\alpha$ subunit (NM_019879) were used for normalization as these genes did not exhibit differential expression in our microarray assays. Sequence of primers used for the real-time RT-PCR is given in supplemental Table 1 (available at www.jneurosci.org as supplemental material).

\section{Results}

\section{Behavioral testing: nociception and analgesia}

Introgression of the Oprm region did not alter baseline sensitivity or analgesic effects of morphine

Baseline sensitivity. There was a significant main effect of genotype $[F$ (genotype) $\mathrm{df}(3,47)=8.67 ; p<0.0001]$ on baseline nociception (Fig. 1A). The B6 and B6D2 genotypes were significantly more sensitive than the D2 and D2B6 mice. The B6 and $\mathrm{B} 6 \mathrm{D} 2$ genotypes did not differ from each other nor did the D2 and D2B6 genotypes. Therefore, baseline pain sensitivity was not affected by the introgression of the proximal region of Chr10.

Acute analgesic sensitivity. There was a significant main effect of genotype on acute sensitivity to the analgesic effects of morphine $[F$ (genotype) $\operatorname{df}(3,23)=35.40 ; p<0.0001]$; the B6 and $\mathrm{B} 6 \mathrm{D} 2$ genotypes were significantly less sensitive than the D2 and D2B6 mice (Fig. $1 \mathrm{~B}$ ). $\mathrm{ED}_{50}$ values for morphine were 4.2 and $5.1 \mathrm{mg} / \mathrm{kg}$ for the D2 and D2B6 mice and 11.8 and $12.2 \mathrm{mg} / \mathrm{kg}$ for the D2 and D2B6 mice, respectively. As was true for baseline nociception, introgression of the proximal Chr10 region did not alter acute sensitivity to the analgesic effects of mor-
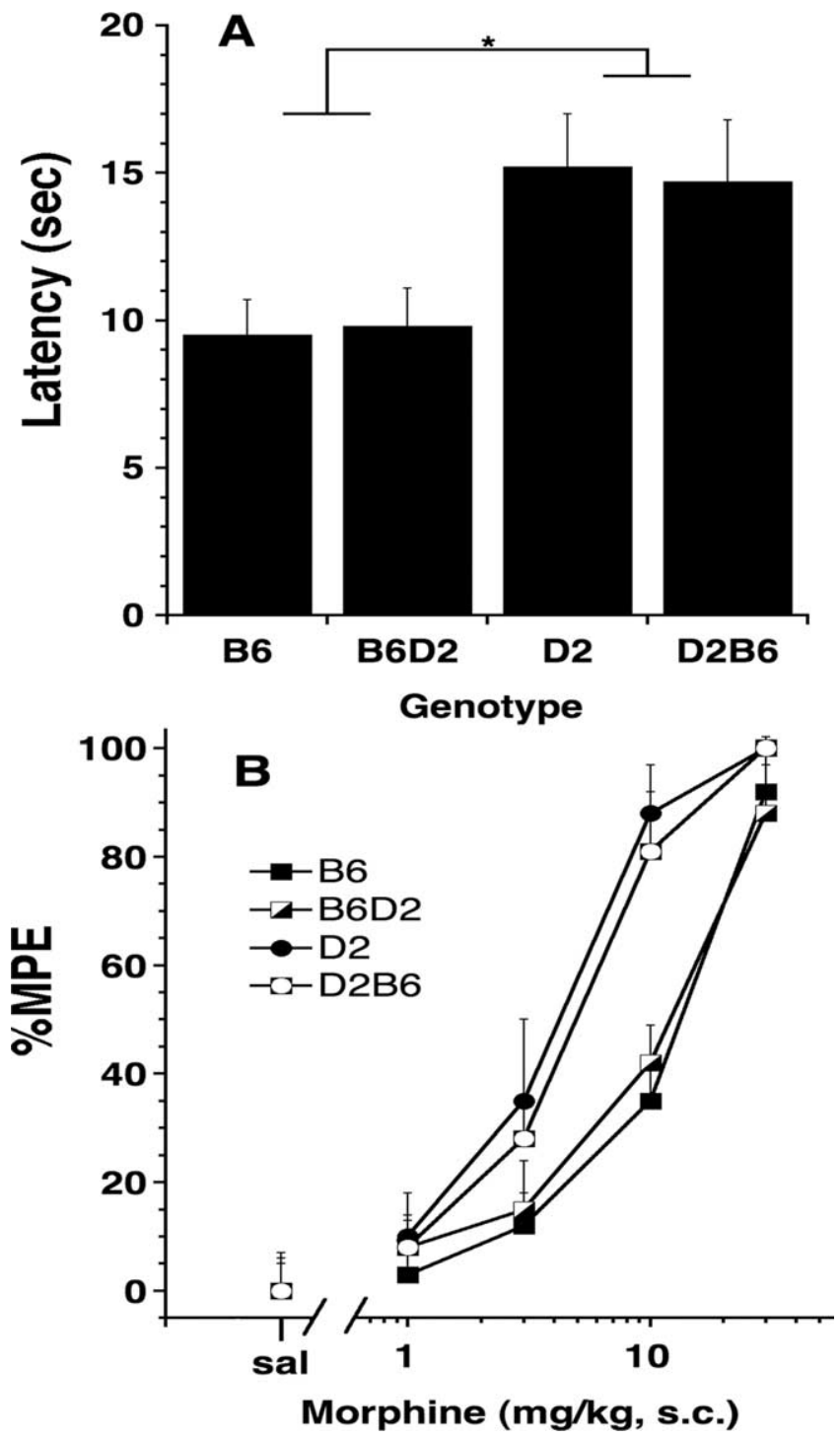

Figure 1. Baseline and acute analgesic effects of morphine. $\boldsymbol{A}$, Baseline nociception. $\boldsymbol{B}$ Dose-response curve at $0,1,5.6,10,30 \mathrm{mg} / \mathrm{kg}$ of morphine. Results are the mean \pm SE of seven to nine animals per genotype. ${ }^{*} p<0.05$.

phine; the B6 and B6D2 genotypes did not differ from each other nor did the D2 and D2B6 genotypes. This was a surprising finding considering bQTL analyses have mapped the proximal chromosome region of 10 to morphine analgesia (Belknap et al., 1995) and other morphine-related behaviors (Berrettini et al., 1994a; Ferraro et al., 2005).

\section{Reciprocal introgression of the Oprm region altered the} development of tolerance

Figure $2 \mathrm{~A}$ (three-injection experiment) shows the analgesic effects of morphine given every other day for $5 \mathrm{~d}$ as a percentage of analgesia produced by the first injection. There was no significance difference in the analgesic effects of morphine after the first injection; therefore, tolerance assessment was performed at approximately equianalgesic doses. Genotype significantly influenced the development of tolerance [ $F$ (genotype) $\mathrm{df}(3,50)=$ $17.25 ; p<0.0005]$. Tolerance developed most rapidly in the B6 followed by the B6D2 strain. Tolerance did not develop in the D2 mice and only slightly in the D2B6 animals. Pairwise compari- 

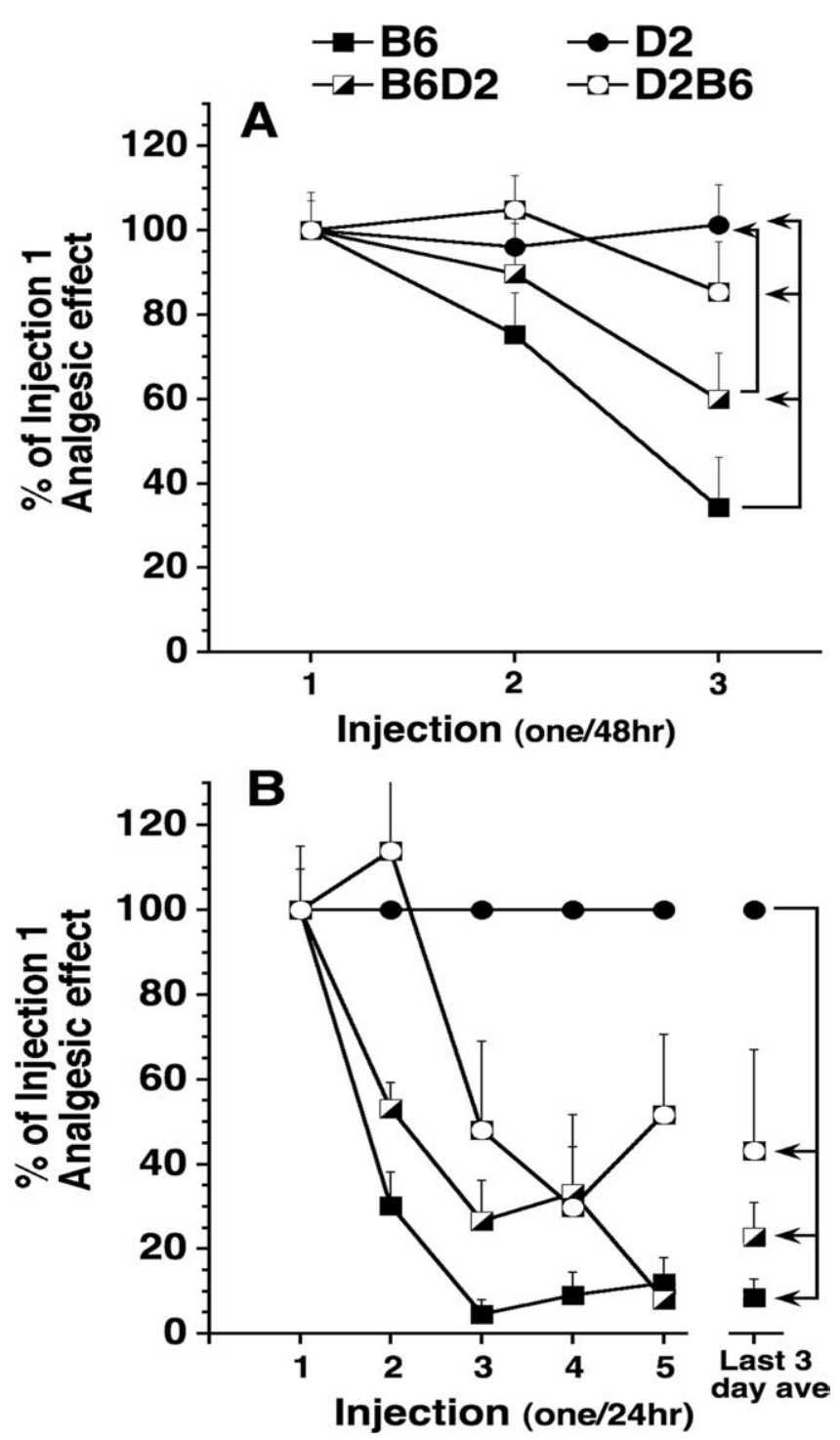

Figure 2. Tolerance to the analgesic effects of morphine. $A$, When the $\mathrm{ED}_{90}$ dose for each genotype is given once every other day for $5 \mathrm{~d}$ (mean \pm SE of $12-16$ animals per genotype). $\boldsymbol{B}$, When given once a day for $5 \mathrm{~d}$ (mean $\pm S E$ of $6-9$ animals per genotype). The average of the last $3 \mathrm{~d}$ is given to the right of the graph for comparison. Arrows indicate significant pairwise comparisons.

sons representing statistical significance after the last injection are delineated by the arrows.

Figure $2 B$ (five injection, phenotype confirmation) shows the analgesic effects of morphine given everyday for $5 \mathrm{~d}$ as a percentage of that produced by the first injection. Again, there was no significant difference in the analgesic effects of morphine after the first injection; therefore, tolerance assessment was performed at approximately equianalgesic doses. Genotype significantly influenced the development of tolerance $[F($ genotype $) \operatorname{df}(3,23)=19.74 ; p<0.0001]$. Tolerance developed most rapidly in the B6 followed by the B6D2 and D2B6 mice. Tolerance did not develop in the D2 mice. Pairwise comparisons (genotype by day) for statistical significance after the last injection are delineated by the arrows. Overall, the shorter dose interval increased the rate of tolerance that developed after three injections [F(treatment schedule) $\operatorname{df}(1,71)=7.19 ; p<0.009]$ as did the additional injections of morphine $[F($ treatment schedule $) \mathrm{df}(1,71)=14.27 ; p<$
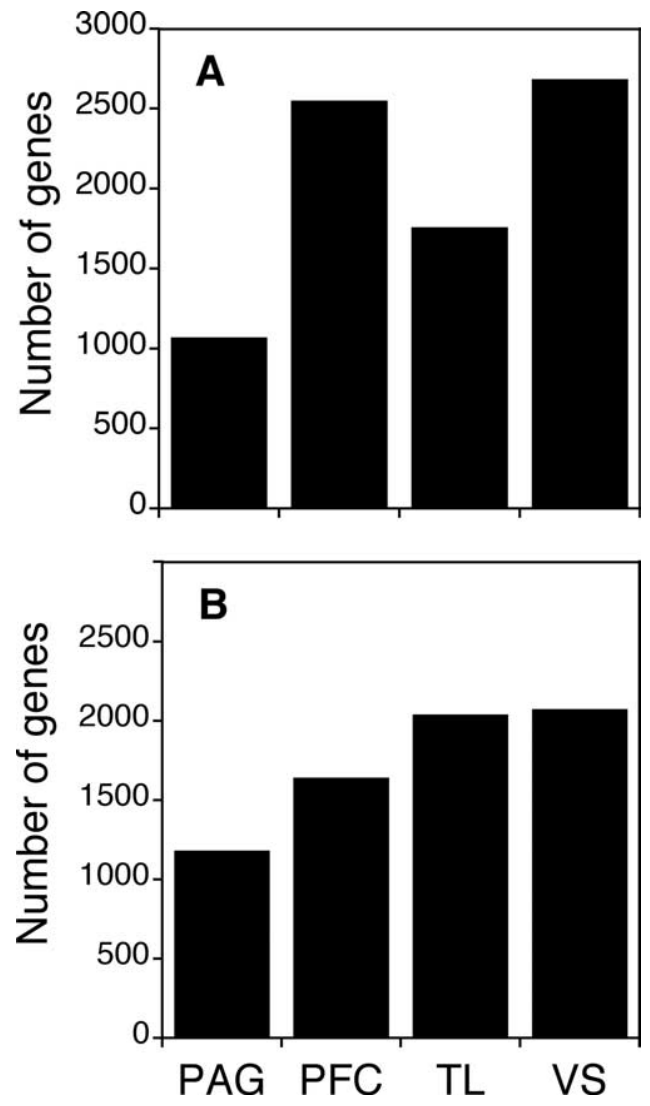

Figure 3. Number of significant gene expression differences across four genotypes in four brain regions. $\boldsymbol{A}$, Genotype signature genes (significant $c g_{s r}$ genes in saline-treated animals). $\boldsymbol{B}$, Morphine signature genes (significant $m g_{s r}-x c g_{s r}$ genes) (see Materials and Methods section for explanation). Statistical significance was defined by ANOVA per brain region with $10 \% \mathrm{FDR}$.

0.0003] (Fig. 2, compare $A, B$ ). However, regardless of the test paradigm, the D2 genotype did not develop tolerance to morphine and there was no genotype by treatment schedule interaction $(p<0.31$; NS); decreasing the interinjection interval and increasing the number of injections produced a parallel change in the development of tolerance across genotypes. Thus, the five-injection phenotype confirmation experiment confirms the results of the three-injection schedule and extends the generality to schedules using a shorter injection interval and more injections.

The degree of tolerance was not influenced by learning factors associated with repeated hot-plate testing. There was no difference between the experimental groups exposed to a heated plate versus those exposed to room temperature plate in the $\mathrm{B} 6 \mathrm{D} 2$ or $\mathrm{B} 6$ genotypes ( $p<0.86, p<0.34$, respectively; both NS) (supplemental Fig. 2, available at www.jneurosci.org as supplemental material).

Microarray gene expression analysis: genotype-dependent differences

The expression profiles of $\sim 21,000 \mathrm{cg}_{s r}$ genes were measured in each of four brain regions (PAG, PFC, TL, VS) across four salinetreated strains (B6, D2, B6D2, D2B6), and a one-way ANOVA (main factor genotype) at 10\% FDR was performed per brain region. Together, a total of 1070, 2550, 1758, and 2684 genotype signature genes were identified $\left(c g_{s r}\right.$ genes exhibiting significant strain-dependent differences in expression of at least 1.5-fold or greater) in the PAG, PFC, TL, and VS, respectively (Fig. 3A; sup- 
plemental Table 2, available at www.jneurosci.org as supplemental material), representing 4562 unique genes across the four brain regions. To define genotype-dependent differences in morphine-induced changes in gene expression, the $\Delta$ value for each gene was computed from the morphine and saline treatment data and subjected to a one-way ANOVA at 10\% FDR per brain region. A total of 1182, 1642, 2041, and 2074 morphine signature genes were detected in the PAG, PFC, TL, VS, respectively (Fig. $3 B$; supplemental Table 2, available at www.jneurosci.org as supplemental material), representing 3942 unique genes across the four brain regions. The number of unique morphine signature genes is not unexpected given the well documented effects of morphine on the expression and/or activity of transcription factors such as $\Delta$ FosB and CREB (Han et al., 2006; Zachariou et al., 2006). The maximum $\Delta /$ minimum $\Delta$ ratio for each gene across the four genotypes ranged from 1.5- to 6-, 1.5- to 8-, 1.5- to 11-, and 1.5 - to 10 -fold in the PAG, PFC, TL, and VS, respectively (data not shown).

\section{Biological themes associated with morphine signature genes} Morphine signature genes ( $\Delta$ genes) were subjected to EASE analysis to identify potential biological themes associated with the four brain regions. Genes were classified by using GO categories belonging to the ontologies of molecular function, biological process, and cellular component. A total of 73, 166, 139, and 144 GO categories were significantly overrepresented (Fisher's exact test, $p<0.05$ ) by morphine signature genes in the PAG, PFC, TL, and VS, respectively. Particularly noteworthy were the identification of epigenetic-related categories such as chromatin remodeling complex (GO:0016585) in the PFC, RNA interference (GO: 0016246) and regulation of cell differentiation (GO:0045595) in the TL, and plasticity-related categories such as neuron development (GO:0048666) and cell projection organization and biogenesis (GO:0030030) in the VS.

\section{Association of gene expression with tolerance across genotypes \\ Gene expression associations with tolerance in different brain regions}

An associative analysis was performed between signature genes and the behavioral endpoint tolerance for candidate gene discovery. Genotype signature genes that correlate with tolerance are postulated to predispose animals to morphine-induced tolerance (such gene associations are termed "predisposition genes"). A similar approach has been used to identify "naive" genes predisposing inbred mice to ethanol-related behaviors (Letwin et al., 2006). The tolerance value [100 - (\%MPE on day 3$)]$ for each genotype was used as the template to search for genotype signature genes (Fig. $3 A$ ); the expression value of a gene across the four genotypes was required to match the tolerance template across the four genotypes to be identified. This was done in each of the four brain regions. Using pattern matching as a correlative search tool (also known as feature selection) (Pavlidis and Noble, 2001), $64,53,86$, and 123 predisposition genes (positive and negative) were identified in the PAG, PFC, TL, and VS, respectively (pattern match $p$ value, $<0.05$ ) (Fig. $4 A$; supplemental Table 3, available at www.jneurosci.org as supplemental material). Tspyl4 and 6330407J23Rik were the only predisposition genes physically located within the congenic region demarcated by markers D10Mit75 and D10Mit61. Using the GeneNetwork eQTL resource (http://www.genenetwork.org), Tspyl4 was found to be regulated in trans by an eQTL locus associated with marker rs3682996 on chromosome 1, whereas 6330407J23Rik was deter- mined to be regulated in cis (supplemental Table 3, available at www.jneurosci.org as supplemental material).

Next, the tolerance value for each genotype was used as the template to search for "tolerance genes" (Fig. 3B) within the morphine signature data set; again, the expression value of a gene across the four genotypes was required to match the tolerance template across the four genotypes to be identified as a candidate gene. Using feature selection, $81,96,106$, and 82 tolerance genes (positive and negative) were identified in the PAG, PFC, TL, and VS, respectively (pattern match $p$ value, $<0.05$ ) (Fig. $4 B$; supplemental Table 3, available at www.jneurosci. org as supplemental material). These genes are postulated to represent potential mediators of tolerance whose expression is modulated by morphine.

We also performed a two-way ANOVA (genotype and treatment serving as the main factors) with $10 \%$ FDR correction in each brain region and subjected the resulting significant genotype by treatment interactions to pattern matching to identify the tolerance genes. Despite the more conservative nature of the twoway ANOVA approach compared with the one-way ANOVA strategy used above, a substantial overlap of pattern-matched genes was found between the two approaches. For example, 79\% of the PFC tolerance genes originally identified by the one-way ANOVA approach were also captured in the two-way ANOVA approach. Overall, the overlap between the two approaches across the four brain regions ranged from $77 \%$ in the PAG to $80 \%$ in the VS. Given the paucity of information pertaining to genes associated with tolerance behavior, all subsequent analyses will be based on the results from the one-way ANOVA.

A phenotype-gene association (PGA) clustergram was generated by hierarchical clustering of the 369 tolerance genes across the four brain regions (Fig. 5). This plot is analogous to hierarchical clustering of gene expression values typically seen in microarray experiments (Eisen et al., 1998); however, rather than clustering one-dimensional expression values, PGA analysis clusters biological information pertaining to the direction and significance level of gene-phenotype correlations (Reiner-Benaim et al., 2007). Tolerance genes exhibiting significant positive correlations are indicated in red, significant negative correlations in green, and nonsignificant correlations in black. Noteworthy in Figure 5 is the paucity of genes that are correlated in more than one brain region $(<2 \%)$. A similar finding was noted for the predisposition set $(<2 \%$ ) (supplemental Table 3, available at www. jneurosci.org as supplemental material). These observations suggest that networks comprised of different combinations of predisposition and/or tolerance genes in each brain region may be working in concert to promote tolerance susceptibility and acquisition. Tolerance genes could be grouped into a number of interesting categories such as gene expression, second messengermediated signaling, neuronal synaptic plasticity, response to oxidative stress, signal transduction/G-protein-coupled receptor and transport (Fig. 5).

\section{In silico mapping of tolerance and predisposition genes to} behavioral and expression QTLS

The mapping of correlated genes to behavioral intervals provides additional supportive evidence when associating a gene to a behavior. Physical map locations of our correlated genes were obtained from ENSEMBL (http://www.ensembl.org) and morphine-related bQTL information was acquired from the literature. Provisional bQTLs mapping to chromosomes 1, 6, and 10 for morphine preference (Berrettini et al., 1994a), chromosomes $3,7,8,9,10,12$, and 18 for morphine consumption 


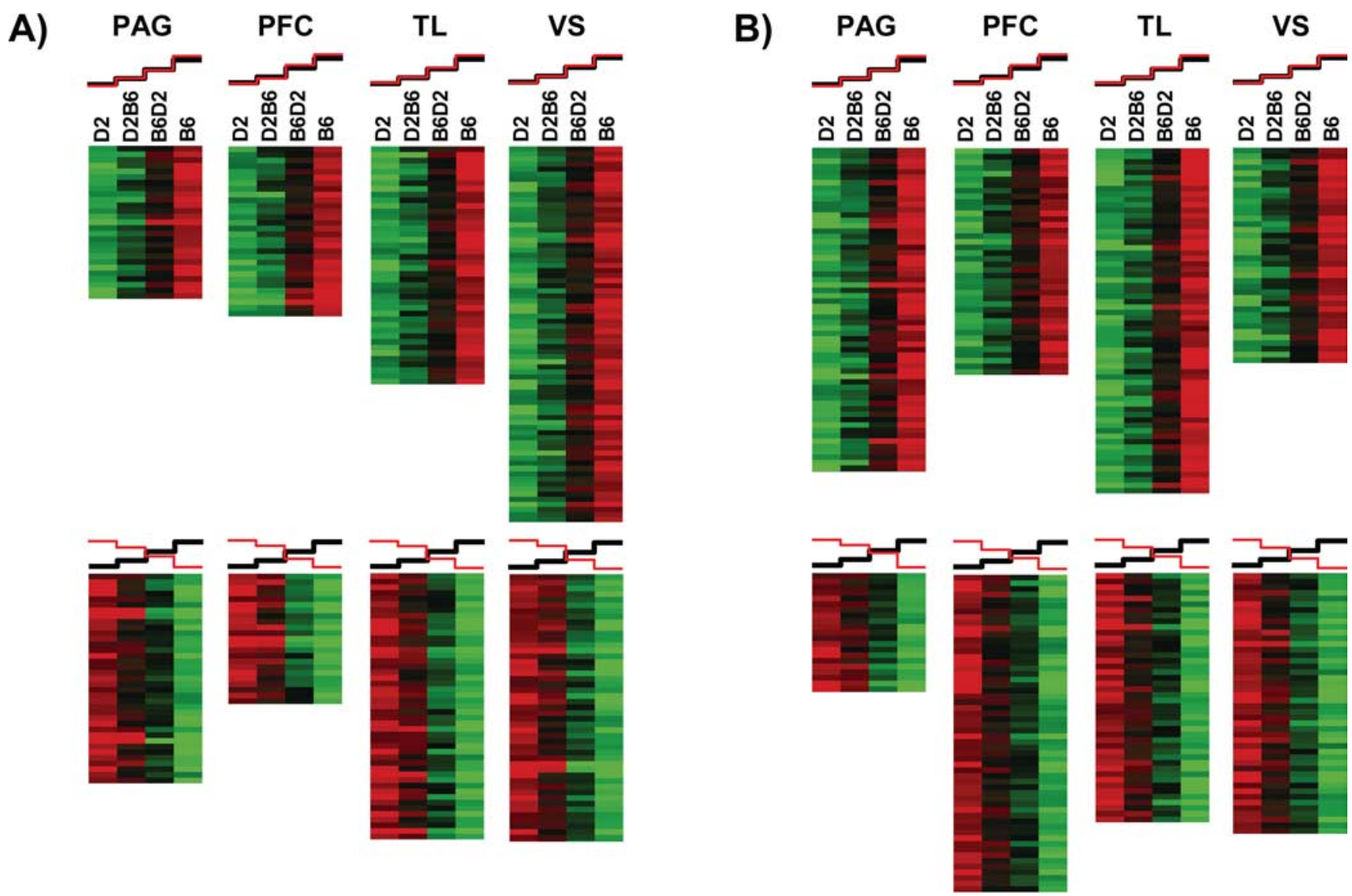

Figure 4. Gene expression correlations with tolerance in different brain regions. $A$, Saline correlations in naive animals. $B, \Delta$ correlations in morphine-treated animals. Cluster images of template matched genes with positive (top panel) and negative correlations (bottom panel). Highly expressed genes are indicated in red, intermediate in black, and weakly expressed in green. Mouse strains are indicated above each column. The black graph above each cluster represents tolerance template values, whereas the red graph represents the mean expression value of all matched genes within each column. Data presented are the mean of $4-12$ hybridizations.

(Belknap and Crabbe, 1992), chromosomes 2, 3, 4, 7, 9, 10, 11, and 19 for morphine analgesia (Belknap and Crabbe, 1992; Belknap et al., 1995; Bergeson et al., 2001), and chromosomes 1, 5 , and 10 for morphine withdrawal (Kest et al., 2004) have been identified through crosses of the B6 and D2 strains, representing $\sim 15 \%$ of the mouse genome. For our analysis, a bQTL interval was defined as two logarithm of odds units around the linkage peak (Rapp, 2000), provided that information on multiple genetic markers in the vicinity of the peak was given (Berrettini et al., 1994a). Otherwise, the interval was defined by 10-15 Mb on either side of a lone genetic marker defining the bQTL. Of the 369 tolerance genes, 316 had unambiguous mapping information, and of these mapped genes $73(23 \%)$ were found to reside in bQTLs that influence morphine-related behaviors (supplemental Table 3, available at www.jneurosci.org as supplemental material). Similar results were obtained in predisposition gene set in which 70 of 258 mapped genes $(27 \%)$ were found to reside in bQTLs (supplemental Table 3, available at www.jneurosci.org as supplemental material). To ascertain whether or not the mapping of correlated genes in bQTLs may have occurred by chance, we compared the number of correlated and noncorrelated genes residing in bQTLs for each brain region. There was a significant occurrence not caused by chance alone of tolerance genes mapping to bQTLs for the TL $\left(\chi^{2}, p=0.0069\right)$ and PAG $\left(\chi^{2}, p=\right.$ $0.0216)$; and predisposition genes mapping to bQTLs for the VS $\left(\chi^{2}, p=0.0059\right)$ and PFC $\left(\chi^{2}, p=0.0221\right)$. A number of interesting tolerance genes residing in bQTLs associated with mor- phine analgesia included the glycine receptor $\beta$ subunit (positively correlated in PAG), signal transducer and activator of transcription 5 (positively correlated in PFC), ADP-ribosylation factor interacting protein 1 (negatively correlated in TL), and tumor suppressor candidate 2 (negatively correlated in VS).

Of the tolerance and predisposition genes residing inside bQTLs but outside of the congenic region, 13 and 6 genes, respectively, were regulated in trans by eQTLs located in the congenic region (supplemental Table 3, available at www.jneurosci.org as supplemental material). Moreover, 39 tolerance and 25 predisposition genes residing outside bQTLs were found to be regulated in trans by eQTLs in the congenic region (supplemental Table 3, available at www.jneurosci.org as supplemental material). There was a significant difference in the occurrence of tolerance versus noncorrelated genes mapping inside eQTLs for the TL $\left(\chi^{2}, p=\right.$ $0.0469)$, VS $\left(\chi^{2}, p=0.0381\right)$, and PAG $\left(\chi^{2}, p=0.0053\right)$; and predisposition versus noncorrelated genes for the TL $\left(\chi^{2}, p=\right.$ $0.0392)$ and PAG $\left(\chi^{2}, p=0.0032\right)$. Notable trans-regulated examples included synaptic vesicle membrane proteins (synaptotagmin XI, syntaxin 3), transcription factors (Stat5a) and extracellular matrix/cell adhesion molecules (laminin B1, integrin $\beta 3$ binding protein).

\section{Identification of gene networks and canonical pathways}

To address whether the correlated genes are potentially interlinked into a gene regulatory network, all predisposition and tolerance genes were computationally analyzed using microarray 
bioinformatics resources available through Ingenuity Pathway Analysis, Pathway Studio, the GO Consortium (www.geneontology. org), GenMAPP (www.genmapp.org), and Kyoto Encyclopedia of Genes and Genomes (www.genome.jp/kegg). Three network "types" can be generated in a regionspecific manner: a network of genes based solely from the predisposition set, a network derived solely from the tolerance set, and a network derived from the combined consideration of predisposition and tolerance genes. The top three networks in each network type for each brain region are provided in supplemental Table 4 (available at www.jneurosci.org as supplemental material). Each network type affords a slightly different viewpoint. The predisposition network may interact in such a way as to provide a genotype-dependent starting "set point" that predisposes the subject to tolerance. These genes may not necessarily change expression in response to morphine but set the stage for the effects of morphine on other genes. The tolerance networks may interact in such a way as to cause (or prevent via compensatory mechanisms) tolerance. These genes do not necessarily differ at baseline; rather they change expression in response to morphine administration in a genotypedependent manner. The combined consideration networks define potential preexisting interactions of predisposition and tolerance genes during the acquisition of tolerance. Promoter analysis of the three network types using the TRANSFAC motif database and MAST (Malek et al., 2006; Lee et al., 2007) did not identify any statistically significant overrepresented transcription factor binding motifs (data not shown).

Figure 6 (right) shows an example network derived from the tolerance gene list in the PAG. Nineteen of the 34 genes in the PAG tolerance network were either positively (12) or negatively (7) associated with the development of tolerance. Eleven of the tolerance genes reside in bQTLs previously associated with morphine-related behaviors (supplemental Table 3, available at www.jneurosci.org as supplemental material). The probability of having 11 of 19 network tolerance genes residing in morphinerelated bQTLs was significantly greater than would be expected by chance alone $\left(\chi^{2}, p<0.0001\right)$. Despite having $<2 \%$ overlap overall between the predisposition and tolerance genes (across all brain regions), seven genes in the PGA tolerance network had corresponding predisposition gene counterparts. As a means to consider the potential alterations in network associations that may occur after chronic drug treatment, Figure 6 (left) shows a simplified network comprised of the seven predisposition gene counterparts (H19, Ttk, Hba2, B4galt1, Hmox1, Casp3, cFos). A comparison of Figure 6 (left and right) was made to demonstrate how prevailing gene networks may undergo alterations in network associations after chronic drug treatment. Some predisposition gene counterparts undergo a reversal in direction of their association with tolerance after morphine treatment (H19, Ttk,
Hba2, B4galt1). For instance, Ttk was positively correlated in saline-treated animals but negatively correlated in animals injected with morphine. $\mathrm{Hba} 2$ in the same network was negatively correlated in saline-treated animals but oppositely correlated on treatment with morphine. Overall, the genes modified by chronic morphine administration show a strong presence in canonical pathways representative of neuroadaptation (see next section) and illustrate potential alterations in network associations after chronic drug administration.

A complementary analysis to the de novo network construction using candidate genes is to determine their representation in molecular pathways with known function. Supplemental Table 5 (available at www.jneurosci.org as supplemental material) presents the top 15 canonical pathways associated with genotype signature, morphine signature, predisposition, and tolerance genes in each brain region along with the number of genes found in each pathway and its corresponding $p$ value. As noted previously, the pathways identified using the genotype and morphine signature lists show a strong presence in canonical pathways representative of neuroadaptation. In this regard, synaptic longterm potentiation (LTP) was identified in the top five genotype and morphine signature lists in the PAG and TL, and PAG and PFC (supplemental Fig. 3, available at www.jneurosci.org as sup- 

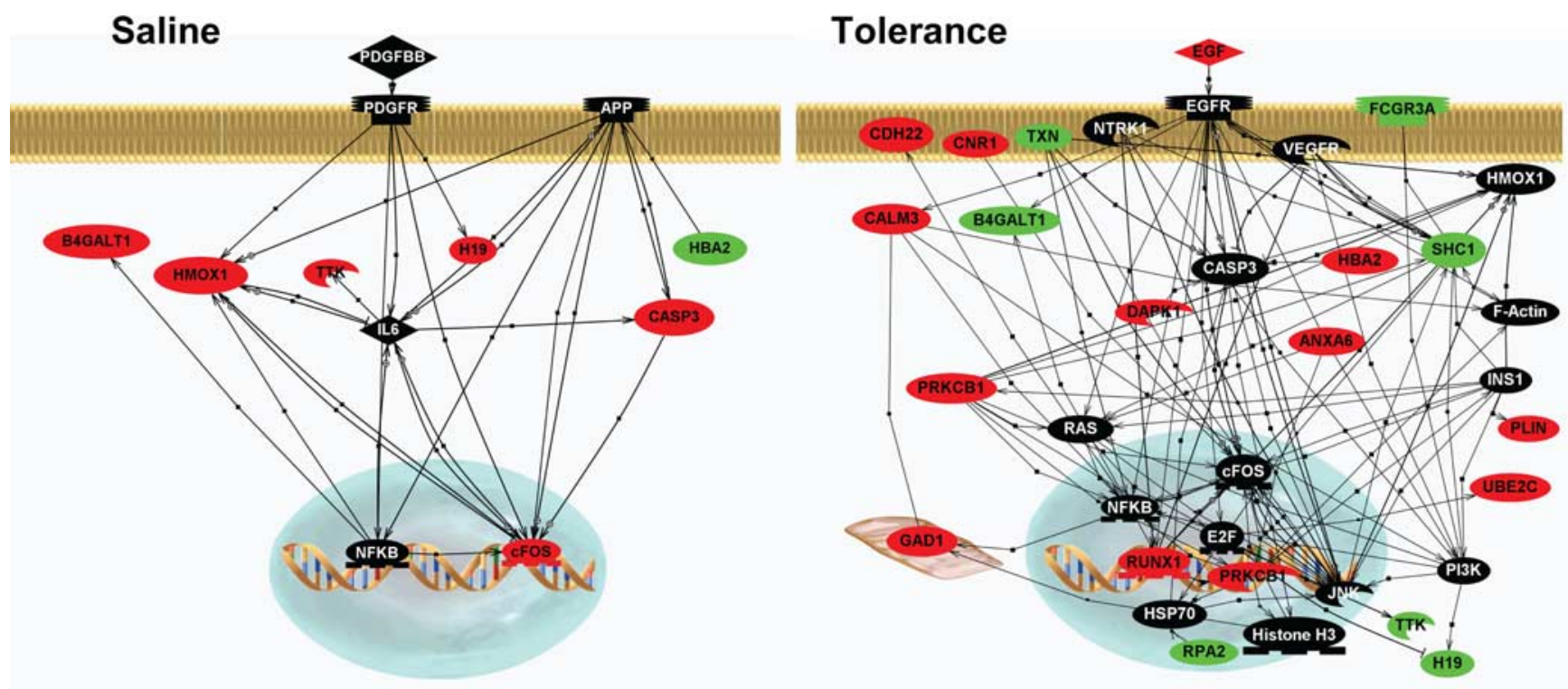

Figure 6. Tolerance gene network in the PAG of saline-treated animals (left) and morphine-treated animals (right). A gene regulatory network with lipid metabolism as the associated biological theme was constructed from the tolerance gene set (correlated morphine signature genes). The correlation status of the same genes in saline-treated animals provides a reference point for the transitioning of drug-naive animals to morphine tolerant animals. Edges (lines) connecting nodes (genes) represent regulatory interactions such as regulation of gene expression, protein-protein interactions, protein-nucleic acid interactions, protein-hormone interactions. Positively correlated genes are indicated in red, noncorrelated in black, and negatively correlated in green. See supplemental Tables 4 and 5 (available at www.jneurosci.org as supplemental material) for definitions of gene symbol abbreviations.

plemental material). Axonal guidance signaling was identified in the top five canonical pathways in all brain regions within genotype signature list and in four of the five brain regions in the morphine signature list. Additional pathways within the morphine signature list suggesting a major role of synaptic plasticity include the ephrin receptor, Huntington's disease, and neuregulin signaling. The smaller number of genes in the predisposition and tolerance lists limit the statistical probability that they will populate a canonical pathway. Nevertheless, there were several pathways in the tolerance list suggestive of neural plasticity [neuregulin, notch, and ERK (extracellular signal-regulated kinase)/ MAPK (mitogen-activated protein kinase) signaling] and cell death [NRF-2 mediated oxidative stress response, GM-CSF (granulocyte-macrophage colony-stimulating factor), and p53 signaling].

\section{Real-time RT-PCR}

Five tolerance genes (protein kinase $\mathrm{C} \gamma$, protein kinase $\mathrm{A} \alpha$ subunit, cannabinoid receptor 1 , adenosine $\mathrm{A}_{1}$ receptor, dicer- 1 protein) involved in six correlations were selected for microarray validation. These genes exhibited the smallest fold change (1.5- to 2 -fold) of maximum $\Delta$ /minimum $\Delta$ across the four strains, presumably representing the lower limits of our analysis to define significant correlations. Protein kinase $\mathrm{C} \gamma$, protein kinase A catalytic $\alpha$ subunit, cannabinoid receptor 1 , and adenosine $A_{1}$ receptor have been implicated in morphine-related behaviors including tolerance, albeit these studies are typically performed in a single mouse strain (Kaplan and Leite-Morris, 1997; Narita et al., 2001; Smith et al., 2006; Trang et al., 2007). It should be noted that none of the aforementioned genes had, before this study, been correlated with tolerance across multiple genetic strains. The fifth gene chosen for validation, dicer-1, has not previously been linked to drug tolerance. Finally, protein kinase A catalytic $\alpha$ subunit and adenosine $A_{1}$ receptor genes were of interest because they mapped to bQTLs associated with morphine consumption and preference, respectively (supplemental Table 3, available at www.jneurosci.org as supplemental material). Quantitative realtime RT-PCR validation of the five genes in six correlations is shown in Figure 7. A significant correlation was found between the microarray and real-time RT-PCR results $(p<0.05)$ and between the RT-PCR results and tolerance behavior for all genes, supporting the reliability of our gene expression measurements.

\section{Discussion}

One of our goals was to investigate the role of the proximal region of Chr10 in the acute and chronic effects of morphine. Previous bQTL studies suggest that this region between markers D10Mit28-D10Mit3 (4-21 cM) accounts for a significant amount of variance in morphine two-bottle choice preference and analgesia (Berrettini et al., 1994a,b; Belknap et al., 1995; Bergeson et al., 2001) (supplemental Fig. 1, available at www. jneurosci.org as supplemental material). A comparison of the B6 and D2 strains in the Mouse Genome Database (http://www. informatics.jax.org) reveals the presence of 21 nonsynonymous coding and 207 noncoding single-nucleotide polymorphisms (SNPs) between D10Mit28 and D10Mit3, which were thought to account for the observed variance in behavioral responses. Oprm, the gene responsible for the primary receptor target of morphine $(\mu \mathrm{OR})$, is located within this region at $8.0 \mathrm{cM}$. Reciprocal introgression of this promising region, however, did not alter baseline nociception or the acute analgesic effects of morphine in our study. These results are in contrast to those found by Bergeson et al. (2001) using a similar congenic approach in which the Chr10 region between markers D10Mit28 and D10Mit3 $(4-21 \mathrm{cM})$ from the donor B6 strain was introgressed into the D2 background (supplemental Fig. 1, available at www.jneurosci.org as supplemental material). In that case, acute sensitivity to $10 \mathrm{mg} / \mathrm{kg}$ morphine (intraperitoneal) was altered in the reciprocal congenic strains; baseline nociception was not reported nor was tolerance assessed. Differences in stimulus intensity, route of administration, endpoint, or alterations in baseline sensitivity (Elmer et al., 1998 ) could contribute to the discrepancy. Equally important is 

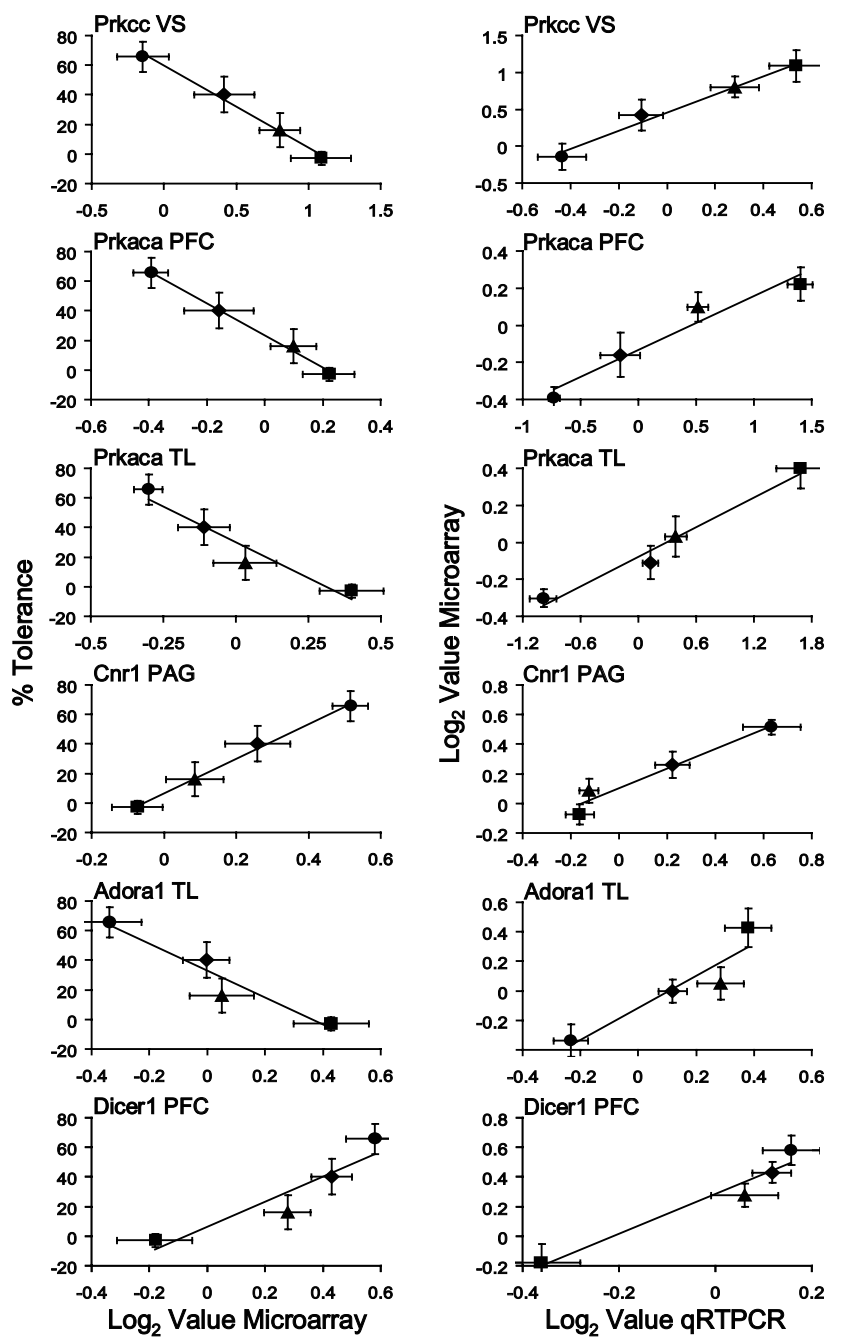

Figure 7. Real time RT-PCR validation of microarray data. Validation of individual template matched genes plotted against tolerance (left panels) and microarray data (right panels). Prkcc VS, Protein kinase C $\gamma$ in ventral striatum (correlation with tolerance, $r=-0.99, p=0.0042$; correlation with microarray data, $r=0.99, p=0.0019)$; Prkaca PFC, protein kinase A catalytic $\alpha$ subunit in prefrontal cortex (correlation with tolerance, $r=-0.99, p=0.0033$; correlation with microarray data, $r=0.97, p=0.028)$; Prkaca TL, protein kinase A catalytic $\alpha$ subunit in temporal lobe (correlation with tolerance, $r=-0.96, p=0.038$; correlation with microarray data, $r=0.99, p=0.013$ ); (nr1 PAG, cannabinoid receptor 1 in periaqueductal gray (correlation with tolerance, $r=0.99, p=0.0023$; correlation with microarray data, $r=0.98, p=$ 0.025); Adora1 TL, adenosine $A_{1}$ receptor in temporal lobe (correlation with tolerance, $r=$ $-0.96, p=0.041$; correlation with microarray data, $r=0.93, p=0.049$ ); Dicer1 PFC, dicer 1 in prefrontal cortex (correlation with tolerance, $r=0.93, p=0.041$; correlation with microarray data, $r=0.98, p=0.024)$. Data are represented as the mean $\pm \mathrm{SE} . \bigcirc, \mathrm{B} 6 ; \bullet, \mathrm{B} 6 \mathrm{D} 2$ congenic; $\mathbf{\Delta}$, D2B6 congenic; $\mathbf{\square}, \mathrm{D} 2$.

the fact that the introgressed regions differ substantially in size between our congenics and the ones studied by Bergeson et al. (2001). Specifically, our D2B6 strain carries an additional $11 \mathrm{cM}$ portion or $37.4 \mathrm{Mb}$ of Chr10 derived from the B6 strain (supplemental Fig. $1 B$, available at www.jneurosci.org as supplemental material). Consequently, genetic interactions (i.e., networks) likely diverge between the two D2B6 lines because of the presence of 162 SNPs residing within 73 genes (many encoding transcription factors) found in this $11 \mathrm{cM}$ region. In fact, 16 of the 162 SNPs have been identified as eQTLs predicted to trans-regulate a subset of our tolerance and predisposition genes. The consequences of different introgressed genetic footprints are analogous to the "congenic footprint" phenomenon, which can lead to pro- found differences in gene expression and behavioral responses (Lee et al., 2007; Schalkwyk et al., 2007). Also noteworthy is our finding that, although reciprocal introgression was without effect on acute morphine analgesia, presumably because of the genetic footprint, profound effects were observed for chronic morphine analgesia. Although differences in environmental context and protocol may ultimately explain a large part of the differences between studies, the difference in introgressed footprint may fortuitously have explanatory significance worth pursuing.

Tolerance to the analgesic effects of morphine develops at a rate directly related to the magnitude of the initial pharmacological effect (Cox and Tiffany, 1997). If the same dose of morphine is used to induce tolerance in subjects that differ significantly in the acute analgesic potency of morphine, tolerance could appear to develop more rapidly in sensitive genotypes given the greater magnitude of the initial pharmacological effect. This confound would affect the tolerance outcome and interpretation. The current study accounts for this by using genotype-specific doses within a "therapeutic" range $\left(\mathrm{ED}_{90}\right)$. Under these conditions, reciprocal introgression of proximal Chr10 altered the development of tolerance. Thus, the acute analgesic effects of morphine are determined in part by genetically separable mechanisms from those that are involved after chronic administration. This conclusion is supported by previous behavior genetic (Oliverio and Castellano, 1974; Kest et al., 2002; Liang et al., 2006), molecular, and pharmacological investigations (Kaneto et al., 1985; Ocaña et al., 2007). A potential confound to this approach is that the genotype-specific $\mathrm{ED}_{90}$ dose is sufficient to produce analgesia acutely in all genotypes but does not reach a threshold for inducing the molecular mechanisms involved in tolerance in all genotypes. If the morphine dose was increased sufficiently to produce tolerance in the D2 mice (i.e., $\sim 10$-fold dose increase produces tolerance in D2) (Kest et al., 2002), a different set of genes may be revealed to produce tolerance. However, this approach also runs the risk of confound by nonspecific neuropharmacological mechanisms engaged at supramaximal dosing.

Given the strong bQTL evidence, a straightforward explanation for differential response to chronic morphine in the B6 and D2 mice would be found in the variations in Oprm expression or protein regulation. In this regard, B6 and D2 mice differ qualitatively in VS $\mu \mathrm{OR}$ regulation after chronic high-dose morphine administration; $\mu \mathrm{OR}$ concentration decreases $(-50 \%)$ in the B6 mice and increases $(+20 \%)$ in the D2 mice (Petruzzi et al., 1997). There are two promoter regions in the Oprm gene, one upstream (5' of exon 11) and one downstream (5' of exon 1) (Liang and Carr, 1997; Pan, 2002). Five SNPs have been identified within a $1.7 \mathrm{~kb}$ region of the Oprm downstream promoter region between the B6 and D2 strains; three were near or within potential transcription binding sites (Doyle et al., 2006). A difference in the basal Oprm promoter activity was seen in vitro between the B6 and D2 constructs, suggesting a role of the polymorphisms in gene transcription (Doyle et al., 2006). However, our current study and those using B6 and D2 constructs in $\mu \mathrm{OR}$-positive $\mathrm{BE}(2)$ cell lines (Doyle et al., 2006) suggest other factors are involved in tolerance in addition to Oprm expression since $\mu \mathrm{OR}$ was not differentially expressed in the cell lines, nor did we find differential expression of the $\mu \mathrm{OR}$ or differential expression of genes known to promote or repress Oprm (Law et al., 2004; Contet et al., 2008). Given the complex and oftentimes controversial evidence surrounding $\mu \mathrm{OR}$ regulation in tolerance, systematic large-scale gene expression analysis may yield alternative molecular mechanisms not found by investigating prototypical candidate mechanisms. 
Large-scale gene expression studies were performed in conjunction with the behavioral studies to identify candidate genes associated with tolerance. A stumbling block in expression studies has been the lack of a systematic method to iteratively focus on the most promising candidates. We used canonical pathway and network analyses to help identify high-value candidate predisposition and tolerance genes. Canonical pathway analysis of the morphine-responsive genes suggests a significant role for neuroadaptive processes in response to chronic morphine administration (i.e., LTP, axonal guidance, ephrin, neuregulin pathways) (for LTP example, see supplemental Fig. 3, available at www. jneurosci.org as supplemental material). Network analysis was used to identify highly interconnected genes to provide insight into molecular events that predispose or are causally related to the development of tolerance. It is possible to analyze and view gene networks from several different vantage points. One viewpoint would be to determine network associations comprised of tolerance genes (Fig. 6, right panel) and determine the correlation status of the same genes before morphine administration (Fig. 6, left panel). An alternative permutation would consist of predisposition genes (supplemental Fig. 3, left panel, available at www.jneurosci.org as supplemental material) and their status after chronic morphine administration (supplemental Fig. 3, right panel, available at www.jneurosci.org as supplemental material). Changes in the correlation status of genes transitioning from baseline to morphine treatment in the network permutations may be of significant interest. This is nicely exemplified by the top network involving tolerance genes in the PAG. Nineteen of the 34 genes in this network were either positively (12) or negatively (7) associated with the development of tolerance. Protein kinase C, cannabinoid receptor 1 , and calmodulin are known to play a prominent role in the current theories of morphine tolerance and neuroadaptation (Law et al., 2000; Williams et al., 2001; Trang et al., 2007; McClung and Nestler, 2008). Of the 19 tolerance genes contributing to this network, more than one-half (11) remarkably resided in bQTLs previously associated with morphinerelated behaviors. The occurrence of these correlated genes in bQTLs was significantly greater than would be expected by chance alone, presumably reflecting their importance in tolerance acquisition. Before morphine administration, 7 of the 34 genes making up this network were found to be associated with tolerance. Three of these genes ( $c$-Fos, Casp, Pld) were not correlated after tolerance developed which could be traced to a parallel morphine response (downregulation) across the genotypes. Strikingly, four genes (B4galt1, Hba2, Ttk, H19) exhibited a reversal in the direction of correlation after chronic morphine administration. For example, high $\mathrm{H} 19$ expression is predictive of tolerance development (direction of predisposition association), and a negative change in expression (i.e., downregulation) is associated with tolerance (direction of tolerance association). H19 expression appears to decrease in the genotypes that become tolerant to morphine and increase in those that do not.

Several recent studies provide intriguing insight into the potential role of $\mathrm{H} 19$ in response to chronic morphine administration. First, it has been suggested that $\mathrm{H} 19$ is a primary micro-RNA precursor (to miR-675) (Cai and Cullen, 2007). Coincidently, our data reveal that Dicer1, encoding the pre-micro-RNA processing enzyme (Bernstein et al., 2001), is associated with the development of tolerance in the PFC, and EASE analysis of morphine-responsive genes identified the RNA interference pathway as playing a role in the TL. Second, analysis of 12,000 genes and ESTs (expressed sequence tags) between control undifferentiated and dedifferentiation derived cell clones establish only one gene as differentially regulated, H19 (Scott et al., 2005). In a separate study, Ayesh et al. (2002) identified 48 differentially expressed genes modulated by $\mathrm{H} 19$ in a manner that may promote metastasis; interestingly, we found that morphine administration altered the expression of $50 \%$ of these genes, but not all were directly associated with the development of tolerance. Third, the H19 imprinting region has been implicated in dopamine neuron differentiation (Freed et al., 2008) and gene regulation via interchromosomal interactions involving the CCCTCbinding factor (Ling et al., 2006). Interestingly, our findings reveal the CCCTC-binding factor to be a genotype signature gene as well. Moreover, five dopamine-related genes (dopamine $\mathrm{D}_{3}$ and $D_{4}$ receptor, dopamine transporter, DARPP-32, and calcyon) were all found to be differentially regulated by morphine in this study. Although none of these genes were found to be correlated with analgesic tolerance, they may be involved in traits such as the rewarding effects of morphine. Overall, our findings suggest that a form of transdifferentiation or metaplasia-like activity may be an important component in the neuroadaptive response to chronic morphine. Thus, although this imprinting region has been recognized as important in neurodevelopment and cellular differentiation, our study suggests that it may play a significant role in response to chronic administration of pharmacologically relevant doses of morphine and warrants future investigation.

In summary, epigenetic and micro-RNA mechanisms and neuroadaptation appear to play a significant role in the nervous systems response to chronic morphine administration as corroborated by converging lines of evidence from EASE/GO, network, and canonical pathway analyses. Specific components of the neuroadaptive response are likely related to specific behavioral endpoints.

\section{References}

Ayesh S, Matouk I, Schneider T, Ohana P, Laster M, Al-Sharef W, De-Groot N, Hochberg A (2002) Possible physiological role of H19 RNA. Mol Carcinog 35:63-74.

Belknap JK, Crabbe JC (1992) Chromosome mapping of gene loci affecting morphine and amphetamine responses in BXD recombinant inbred mice. Ann N Y Acad Sci 654:311-323.

Belknap JK, Mogil JS, Helms ML, Richards SP, O’Toole LA, Bergeson SE, Buck KJ (1995) Localization to chromosome 10 of a locus influencing morphine analgesia in crosses derived from C57BL/6 and DBA/2 strains. Life Sci 57:PL117-PL124.

Bergeson SE, Helms ML, O’Toole LA, Jarvis MW, Hain HS, Mogil JS, Belknap JK (2001) Quantitative trait loci influencing morphine antinociception in four mapping populations. Mamm Genome 12:546-553.

Bernstein E, Caudy AA, Hammond SM, Hannon GJ (2001) Role for a bidentate ribonuclease in the initiation step of RNA interference. Nature 409:363-366.

Berrettini WH, Ferraro TN, Alexander RC, Buchberg AM, Vogel WH (1994a) Quantitative trait loci mapping of three loci controlling morphine preference using inbred mouse strains. Nat Genet 7:54-58.

Berrettini WH, Alexander R, Ferraro TN, Vogel WH (1994b) A study of oral morphine preference in inbred mouse strains. Psychiatr Genet 4:81-86.

Cai X, Cullen BR (2007) The imprinted H19 noncoding RNA is a primary microRNA precursor. RNA 13:313-316.

Chudler EH, Dong WK (1995) The role of the basal ganglia in nociception and pain. Pain 60:3-38.

Contet C, Filliol D, Matifas A, Kieffer BL (2008) Morphine-induced analgesic tolerance, locomotor sensitization and physical dependence do not require modification of mu opioid receptor, cdk5 and adenylate cyclase activity. Neuropharmacology 54:475-486.

Cox LS, Tiffany ST (1997) Associative and nonassociative tolerance: the effects of dose and interdose interval. Pharmacol Biochem Behav 57:31-36.

Doyle GA, Sheng XR, Schwebel CL, Ferraro TN, Berrettini WH, Buono RJ (2006) Identification and functional significance of polymorphisms in the mu-opioid receptor gene (Oprm) promoter of C57BL/6 and DBA/2 mice. Neurosci Res 55:244-254. 
Eisen MB, Spellman PT, Brown PO, Botstein D (1998) Cluster analysis and display of genome-wide expression patterns. Proc Natl Acad Sci U S A 95:14863-14868.

Elmer GI, Pieper JO, Negus SS, Woods JH (1998) Genetic variance in nociception and its relationship to the potency of morphine-induced analgesia in thermal and chemical tests. Pain 75:129-140.

Everitt BJ, Parkinson JA, Olmstead MC, Arroyo M, Robledo P, Robbins TW (1999) Associative processes in addiction and reward. The role of amygdala-ventral striatal subsystems. Ann NY Acad Sci 877:412-438.

Ferraro TN, Golden GT, Smith GG, Martin JF, Schwebel CL, Doyle GA, Buono RJ, Berrettini WH (2005) Confirmation of a major QTL influencing oral morphine intake in C57 and DBA mice using reciprocal congenic strains. Neuropsychopharmacology 30:742-746.

Freed WJ, Chen J, Bäckman CM, Schwartz CM, Vazin T, Cai J, Spivak CE, Lupica CR, Rao MS, Zeng X (2008) Gene expression profile of neuronal progenitor cells derived from hESCs: activation of chromosome 11 p15.5 and comparison to human dopaminergic neurons. PLoS ONE 3:e1422.

Grice DE, Reenilä I, Männistö PT, Brooks AI, Smith GG, Golden GT, Buxbaum JD, Berrettini WH (2007) Transcriptional profiling of C57 and DBA strains of mice in the absence and presence of morphine. BMC Genomics 8:76.

Han MH, Bolaños CA, Green TA, Olson VG, Neve RL, Liu RJ, Aghajanian GK, Nestler EJ (2006) Role of cAMP response element-binding protein in the rat locus ceruleus: regulation of neuronal activity and opiate withdrawal behaviors. J Neurosci 26:4624-4629.

Hardy SG, Haigler HJ (1985) Prefrontal influences upon the midbrain: a possible route for pain modulation. Brain Res 339:285-293.

Hosack DA, Dennis G Jr, Sherman BT, Lane HC, Lempicki RA (2003) Identifying biological themes within lists of genes with EASE. Genome Biol 4:R70.

Joe B, Letwin NE, Garrett MR, Dhindaw S, Frank B, Sultana R, Verratti K, Rapp JP, Lee NH (2005) Transcriptional profiling with a blood pressure QTL interval-specific oligonucleotide array. Physiol Genomics 23:318-326.

Kaneto H, Yamazaki A, Kihara T (1985) Evidence for the dissociation of morphine analgesia, tolerance and dependence. J Pharm Pharmacol 37:507-508.

Kaplan GB, Leite-Morris KA (1997) Up-regulation of adenosine transporter-binding sites in striatum and hypothalamus of opiate tolerant mice. Brain Res 763:215-220.

Kest B, Hopkins E, Palmese CA, Adler M, Mogil JS (2002) Genetic variation in morphine analgesic tolerance: a survey of 11 inbred mouse strains. Pharmacol Biochem Behav 73:821-828.

Kest B, Palmese CA, Juni A, Chesler EJ, Mogil JS (2004) Mapping of a quantitative trait locus for morphine withdrawal severity. Mamm Genome 15:610-617.

Korostynski M, Kaminska-Chowaniec D, Piechota M, Przewlocki R (2006) Gene expression profiling in the striatum of inbred mouse strains with distinct opioid-related phenotypes. BMC Genomics 7:146.

Korostynski M, Piechota M, Kaminska D, Solecki W, Przewlocki R (2007) Morphine effects on striatal transcriptome in mice. Genome Biol 8:R128.

Law PY, Wong YH, Loh HH (2000) Molecular mechanisms and regulation of opioid receptor signaling. Annu Rev Pharmacol Toxicol 40:389-430.

Law PY, Loh HH, Wei LN (2004) Insights into the receptor transcription and signaling: implications in opioid tolerance and dependence. Neuropharmacology 47:300-311.

Lee NH, Saeed AI (2007) Microarrays: an overview. Methods Mol Biol 265-300.

Lee NH, Haas BJ, Letwin NE, Frank BC, Luu TV, Sun Q, House CD, YergaWoolwine S, Farms P, Manickavasagam E, Joe B (2007) Cross-talk of expression quantitative trait loci within 2 interacting blood pressure quantitative trait loci. Hypertension 50:1126-1133.

Letwin NE, Kafkafi N, Benjamini Y, Mayo C, Frank BC, Luu T, Lee NH, Elmer GI (2006) Combined application of behavior genetics and microarray analysis to identify regional expression themes and gene-behavior associations. J Neurosci 26:5277-5287.

Liang DY, Guo T, Liao G, Kingery WS, Peltz G, Clark JD (2006) Chronic pain and genetic background interact and influence opioid analgesia, tolerance, and physical dependence. Pain 121:232-240.
Liang M, Lee NH, Wang H, Greene AS, Kwitek AE, Kaldunski ML, Luu TV, Frank BC, Bugenhagen S, Jacob HJ, Cowley AW Jr (2008) Molecular networks in Dahl salt-sensitive hypertension based on transcriptome analysis of a panel of consomic rats. Physiol Genomics 34:54-64.

Liang Y, Carr LG (1997) Transcription of the mouse mu-opioid receptor gene is regulated by two promoters. Brain Res 769:372-374.

Ling JQ, Li T, Hu JF, Vu TH, Chen HL, Qiu XW, Cherry AM, Hoffman AR (2006) CTCF mediates interchromosomal colocalization between Igf2/ H19 and Wsb1/Nf1. Science 312:269-272.

Malek RL, Irby RB, Guo QM, Lee K, Wong S, He M, Tsai J, Frank B, Liu ET, Quackenbush J, Jove R, Yeatman TJ, Lee NH (2002) Identification of Src transformation fingerprint in human colon cancer. Oncogene 21:7256-7265.

Malek RL, Wang HY, Kwitek AE, Greene AS, Bhagabati N, Borchardt G, Cahill L, Currier T, Frank B, Fu X, Hasinoff M, Howe E, Letwin N, Luu TV, Saeed A, Sajadi H, Salzberg SL, Sultana R, Thiagarajan M, Tsai J, et al. (2006) Physiogenomic resources for rat models of heart, lung and blood disorders. Nat Genet 38:234-239.

Manning BH, Morgan MJ, Franklin KB (1994) Morphine analgesia in the formalin test: evidence for forebrain and midbrain sites of action. Neuroscience 63:289-294.

Mas M, Sabater E, Olaso MJ, Horga JF, Faura CC (2000) Genetic variability in morphine sensitivity and tolerance between different strains of rats. Brain Res 866:109-115.

McClung CA, Nestler EJ (2008) Neuroplasticity mediated by altered gene expression. Neuropsychopharmacology 33:3-17.

Nandigama P, Borszcz GS (2003) Affective analgesia following the administration of morphine into the amygdala of rats. Brain Res 959:343-354.

Narita M, Aoki T, Ozaki S, Yajima Y, Suzuki T (2001) Involvement of protein kinase Cgamma isoform in morphine-induced reinforcing effects. Neuroscience 103:309-314.

Ocaña M, Entrena JM, Baeyens JM, Del Pozo E (2007) The antinociceptive effect of morphine is reversed by okadaic acid in morphine-naive but not in morphine-tolerant mice. Pharmacol Biochem Behav 86:21-26.

Oliverio A, Castellano C (1974) Genotype-dependent sensitivity and tolerance to morphine and heroin: dissociation between opiate-induced running and analgesia in the mouse. Psychopharmacologia 39:13-22.

Pan YX (2002) Identification and characterization of a novel promoter of the mouse mu opioid receptor gene (Oprm) that generates eight splice variants. Gene 295:97-108.

Pavlidis P, Noble WS (2001) Analysis of strain and regional variation in gene expression in mouse brain. Genome Biol 2:RESEARCH0042.

Pavlovic ZW, Cooper ML, Bodnar RJ (1996) Opioid antagonists in the periaqueductal gray inhibit morphine and beta-endorphin analgesia elicited from the amygdala of rats. Brain Res 741:13-26.

Paxinos G, Franklin KBG (2001) The mouse brain in stereotaxic coordinates, Ed 2. San Diego: Academic.

Petruzzi R, Ferraro TN, Kürschner VC, Golden GT, Berrettini WH (1997) The effects of repeated morphine exposure on mu opioid receptor number and affinity in C57BL/6J and DBA/2J mice. Life Sci 61:2057-2064.

Rapp JP (2000) Genetic analysis of inherited hypertension in the rat. Physiol Rev 80:135-172.

Reiner A, Yekutieli D, Benjamini Y (2003) Identifying differentially expressed genes using false discovery rate controlling procedures. Bioinformatics 19:368-375.

Reiner-Benaim A, Yekutieli D, Letwin NE, Elmer GI, Lee NH, Kafkafi N, Benjamini Y (2007) Associating quantitative behavioral traits with gene expression in the brain: searching for diamonds in the hay. Bioinformatics 23:2239-2246.

Schalkwyk LC, Fernandes C, Nash MW, Kurrikoff K, Vasar E, Kõks S (2007) Interpretation of knockout experiments: the congenic footprint. Genes Brain Behav 6:299-303.

Scott RE, Gao S, Kim CK, Cox R (2005) De-differentiation-derived mesenchymal stem cells demonstrate selective repression in H19 bioregulatory RNA gene expression. Differentiation 73:294-302.

Shippenberg TS, Elmer GI (1998) The neurobiology of opiate reinforcement. Crit Rev Neurobiol 12:267-303.

Smith FL, Javed RR, Smith PA, Dewey WL, Gabra BH (2006) PKC and PKA inhibitors reinstate morphine-induced behaviors in morphine tolerant mice. Pharmacol Res 54:474-480.

Tanaka TS, Jaradat SA, Lim MK, Kargul GJ, Wang X, Grahovac MJ, Pantano 
S, Sano Y, Piao Y, Nagaraja R, Doi H, Wood WH 3rd, Becker KG, Ko MS (2000) Genome-wide expression profiling of mid-gestation placenta and embryo using a 15,000 mouse developmental cDNA microarray. Proc Natl Acad Sci U S A 97:9127-9132.

Teramoto H, Castellone MD, Malek RL, Letwin N, Frank B, Gutkind JS, Lee NH (2005) Autocrine activation of an osteopontin-CD44-Rac pathway enhances invasion and transformation by H-RasV12. Oncogene 24:489-501.

Tortorici V, Morgan MM, Vanegas H (2001) Tolerance to repeated microinjection of morphine into the periaqueductal gray is associated with changes in the behavior of off- and on-cells in the rostral ventromedial medulla of rats. Pain 89:237-244.

Trang T, Sutak M, Jhamandas K (2007) Involvement of cannabinoid (CB1)receptors in the development and maintenance of opioid tolerance. Neuroscience 146:1275-1288.
Williams JT, Christie MJ, Manzoni O (2001) Cellular and synaptic adaptations mediating opioid dependence. Physiol Rev 81:299-343.

Wise RA (1996) Neurobiology of addiction. Curr Opin Neurobiol 6:243-251.

Yang IV, Chen E, Hasseman JP, Liang W, Frank BC, Wang S, Sharov V, Saeed AI, White J, Li J, Lee NH, Yeatman TJ, Quackenbush J (2002) Within the fold: assessing differential expression measures and reproducibility in microarray assays. Genome Biol 3:research0062.

Zachariou V, Bolanos CA, Selley DE, Theobald D, Cassidy MP, Kelz MB, Shaw-Lutchman T, Berton O, Sim-Selley LJ, Dileone RJ, Kumar A, Nestler EJ (2006) An essential role for DeltaFosB in the nucleus accumbens in morphine action. Nat Neurosci 9:205-211.

Zubieta JK, Smith YR, Bueller JA, Xu Y, Kilbourn MR, Jewett DM, Meyer CR, Koeppe RA, Stohler CS (2001) Regional mu opioid receptor regulation of sensory and affective dimensions of pain. Science 293:311-315. 